\title{
Staphylococcus Aureus Pigment-Bio Colour as a Novel Antibacterial Agent Against Staphylococcus Aureus Isolate from Coins
}

\author{
Ayisha Begum, M. K. Aishwarya, Aeliya Zehra. M, Achiffa Abdul Rahiman, R. Ushasri \\ P.G. Department of Applied Microbiology, JBAS College for Women, Chennai, Tamil Nadu, India
}

\begin{abstract}
The pathogen Staphylococcus aureus is Gram-positive cocci in clusters which forms golden colony on Nutrient agar. The most important characteristic feature of Staphylococcus aureus is its yellow to orange colour due to production of Staph ylox an thin. Staphyloxanthin is membrane bound Carotenoid and plays an important role in antimicrobial activity. The aim of the present study was to detect the role of Staphyloxanthin pigment production from S. aureus isolates against Staphylococcus aureus isolate from coin proving antagonistic property. The crude ethanol pigment was used against staphylococcus aureus in different concentrations ranging from $500 \mu 1$ to $62.5 \mu \mathrm{l}$ by well diffusion method. Minimum inhibition was found to be $11 \mathrm{~mm}$ at concentration range of 500. $\mu 1$. The current study reported that coin plays an important role s transmitting infections
\end{abstract}

Keywords: Staphyloxanthin, Carotenoid, MHA, MSA

\section{INTRODUCTION}

The pathogen Staphylococcus au re us is Grampositive cocci in clusters which forms golden colony on Nutrient agar. The most important characteristic feature of Staphylococcus au re us is its yellow to orange colour due to production of Staphyloxanthin. Staphyloxanthin is membrane bound carotenoid and plays an important role in antimicrobial activity. Membrane pigments acts as virulence factors in S. aureus. Staph yloxan thin is a secondary metabolite produced during stationary phase which has a chemical formula of (C51H78O8). Staphyloxanthin is a neutral molecule. The aim of the present study was to detect the role of Staphyloxanthin pigment production from $S$. aureus isolates against
Staphylococcus aureus isolate from coin proving antagonistic property. Nutrient agar, Brain Heart infusion agar, Milk agar medium, Pea nut seed medium, Sunflowers seeds medium, Sesame seed medium, Trypticase yeast agar medium, , Carotenoid expression agar medium were used for production of staphyloxanthin. The pigment of Staphylococcus aureus (STX) was extracted by using Ethanol .Bacterial cells were recovered from the growth on Nutrient agar plate at $37 \mathrm{oC}$. The bacterial cells were centrifuged at 2000rpm for 15 min. Staphyloxanthin from the pellet containing the bacterial cells was collected. The pellet was mixed with $8 \mathrm{ml}$ of $99.9 \%$ Ethanol wrapped with aluminum foil to avoid light exposure and kept in oven for $72 \mathrm{hrs}$ to obtain crude extract.. Carotenoids were estimated quantitatively by measuring the absorbance of the solution at $450 \mathrm{~nm}$. The crude pigment extracts were evaluated for antibacterial activity against staphylococcus aureus isolate from coins collected from crowded area.

\section{METHODOLOGY}

\section{Sample Collection}

The coin were collected in crowded area from petty shop and transport in zip lock cover using sterile hand gloves and transferred to sterile broth for sample processing.

\section{Sample Processing}

The samples were then processed by inoculating into the nutrient broth and incubated for 24 hours at $37^{\circ} \mathrm{C}$ for determining the growth of organism followed by centrifugation. The organisms in the samples were then identified by microscopic, cultural and biochemical tests as Staphylococcus aureus. 


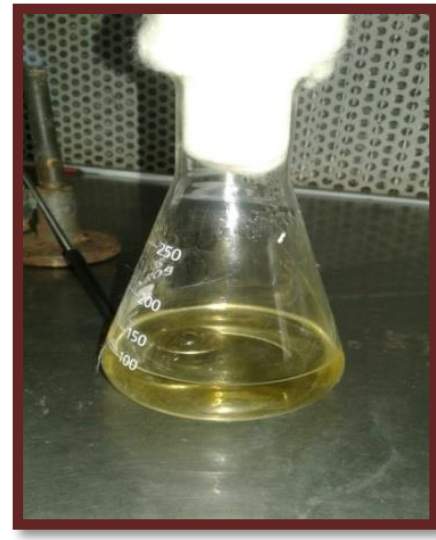

Coin in nutrient broth

\section{Identification of Staphylococcus}

Staphylococcus was identified by Gram staining, Hanging drop, catalase, and oxidase tests. The cultural characteristics and biochemical characters were performed to identify Staphylococcus.

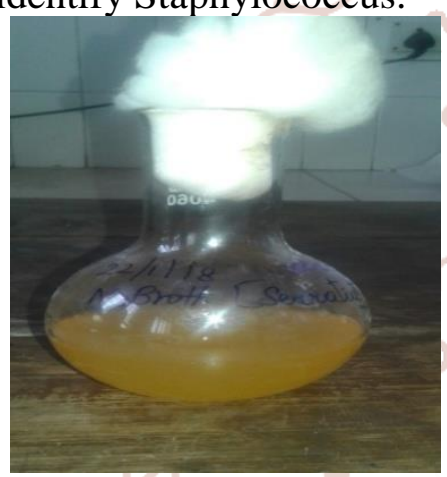

Inoculation of staphylococcus aureus In to nutrient broth

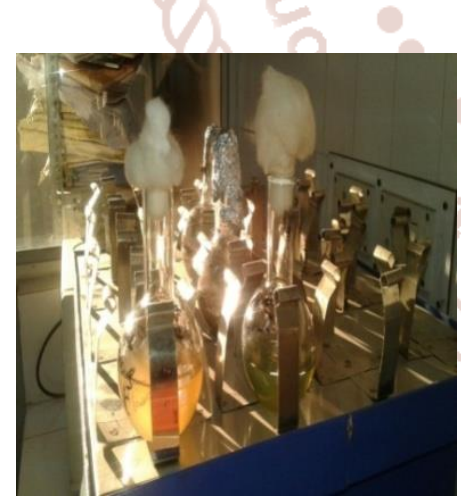

Incubation of pigmented broth in rotary shaker at $37^{\circ} \mathrm{c}$

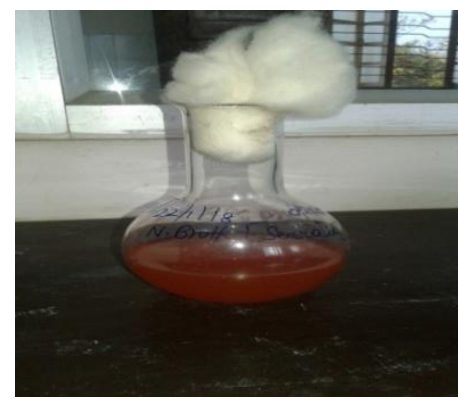

Red pigmented broth after 48 hrs.

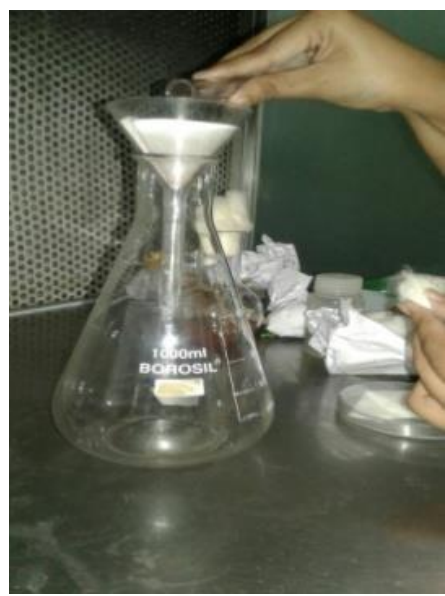

Filtration of centrifuged supernatant broth

\section{Extraction of pigment}

The pigmented broth was transferred to sterile tubes and centrifuged for $30 \mathrm{mins}$ at $1500 \mathrm{rpm}$. The supernatant was filtered by using sterile whats Mann filter paper. The filtrate was extracted using ethanol solvent. The filtrate was evaporated to extract crude pigment and stored in vials for antibacterial activity.
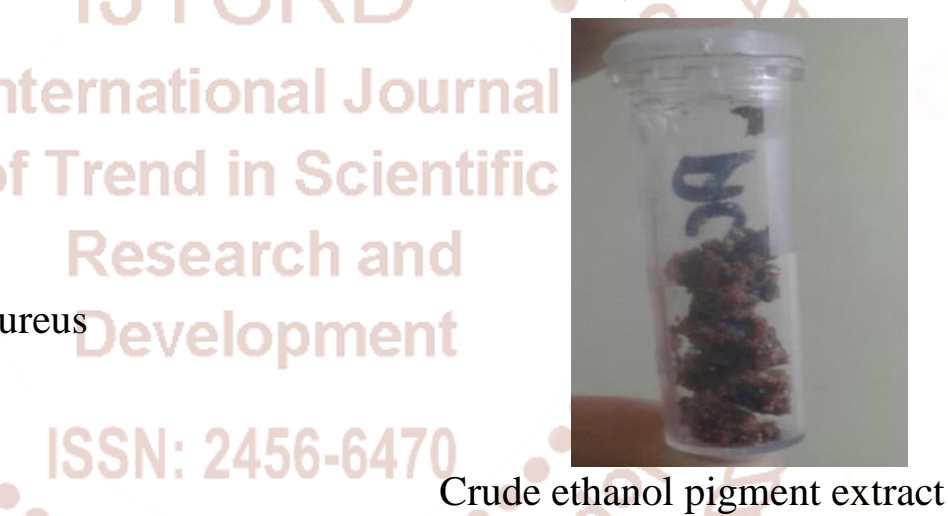

Crude ethanol pigment extract

\section{MICROSCOPIC APPEARANCE}

The inoculated colonies were observed for microscopic appearance and identified as motile gram positive cocci in clusters.

Gram positive cocci in clusters

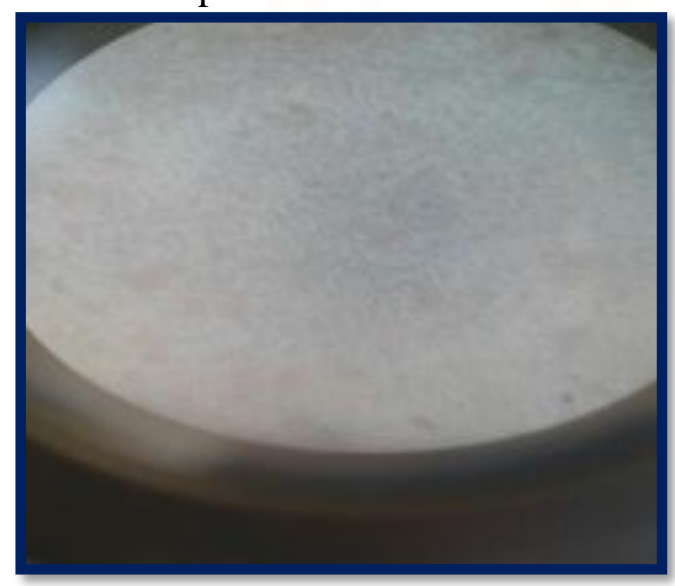




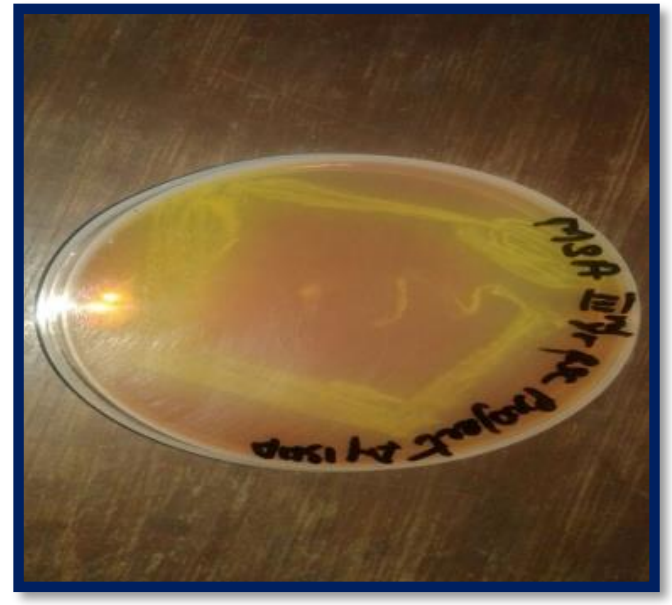

Yellow colonies on Mannitol salt agar

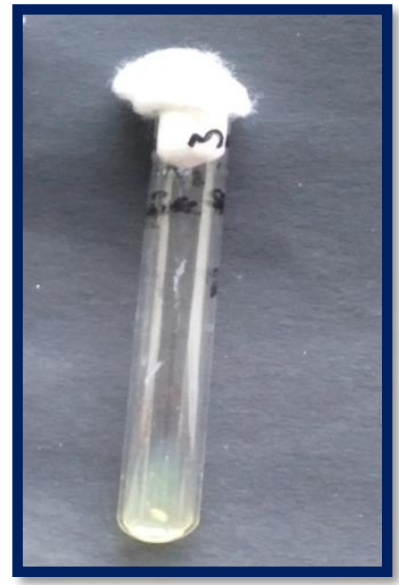

Coagulase positive - S.aureus
Preliminary Tests of Staphylococcus Aureus

\begin{tabular}{|l|l|l|}
\hline Sl. no & \multicolumn{1}{|c|}{ Tests } & Observation \\
\hline 1. & $\begin{array}{l}\text { Gram } \\
\text { staining }\end{array}$ & $\begin{array}{l}\text { Gram-Positive } \\
\text { cocci in clusters }\end{array}$ \\
\hline 2. & Motility & Non motile \\
\hline 3. & Catalase & Postive \\
\hline 4. & Oxidase & Negative \\
\hline
\end{tabular}

\section{Antibiotic sensitivity test for the S. aureus}

S.aureus was found highly sensitive to Erythromycin followed by sensitive to clindamycin and vancomycin and resistant to the antibiotic Penicillin.

\begin{tabular}{|c|c|c|}
\hline Sl. no & Antibiotics & Zone of Inhibition \\
\hline 1. & Vancomycin & $13 \mathrm{~mm}$ \\
\hline 2. & Erythromycin & $25 \mathrm{~mm}$ \\
\hline 3. & Clindamycin & $17 \mathrm{~mm}$ \\
\hline 4. & Penicillin & Resistant \\
\hline
\end{tabular}

\section{Cultural Characters of Staphylococcus Aureus}

\begin{tabular}{|c|c|c|}
\hline $\begin{array}{l}\text { S. } \\
\text { No }\end{array}$ & $\begin{array}{c}\text { Colony } \\
\text { morphology }\end{array}$ & Inference \\
\hline 1. & Size and colour & $\begin{array}{l}1-2 \mathrm{~mm} \text { and yellov } \\
\text { colonies }\end{array}$ \\
\hline 2. & Margin & Entire \\
\hline 3. & Shape & Circular \\
\hline 4. & Opacity & Opaque \\
\hline 5. & Consistency & Smooth \\
\hline 6. & Elevation & Convex \\
\hline
\end{tabular}

\section{Biochemical Characters of Staphylococcus Aureus}

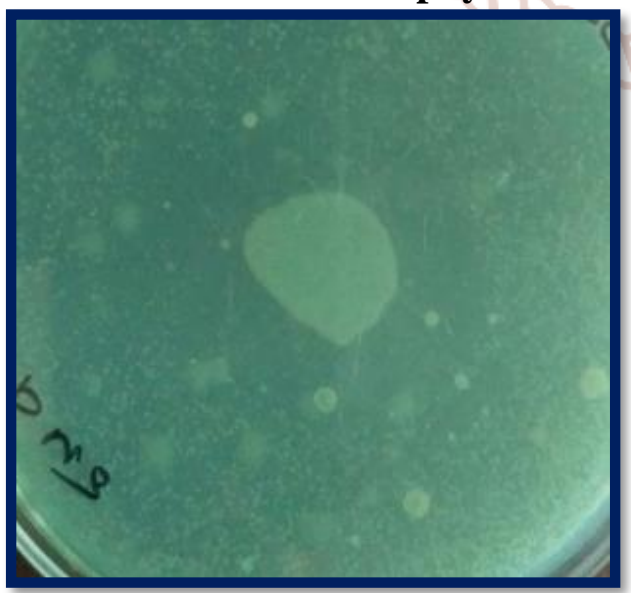

DNAse positive - S.aureus
Isolation and identification of Staphylococcus aureus from coin

Gram positive cocci in cluster

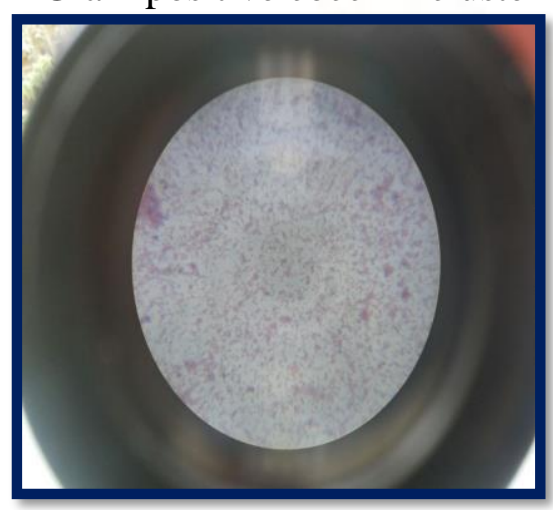


International Journal of Trend in Scientific Research and Development (IJTSRD) ISSN: 2456-6470

Yellow colonies on Mann itol salt agar
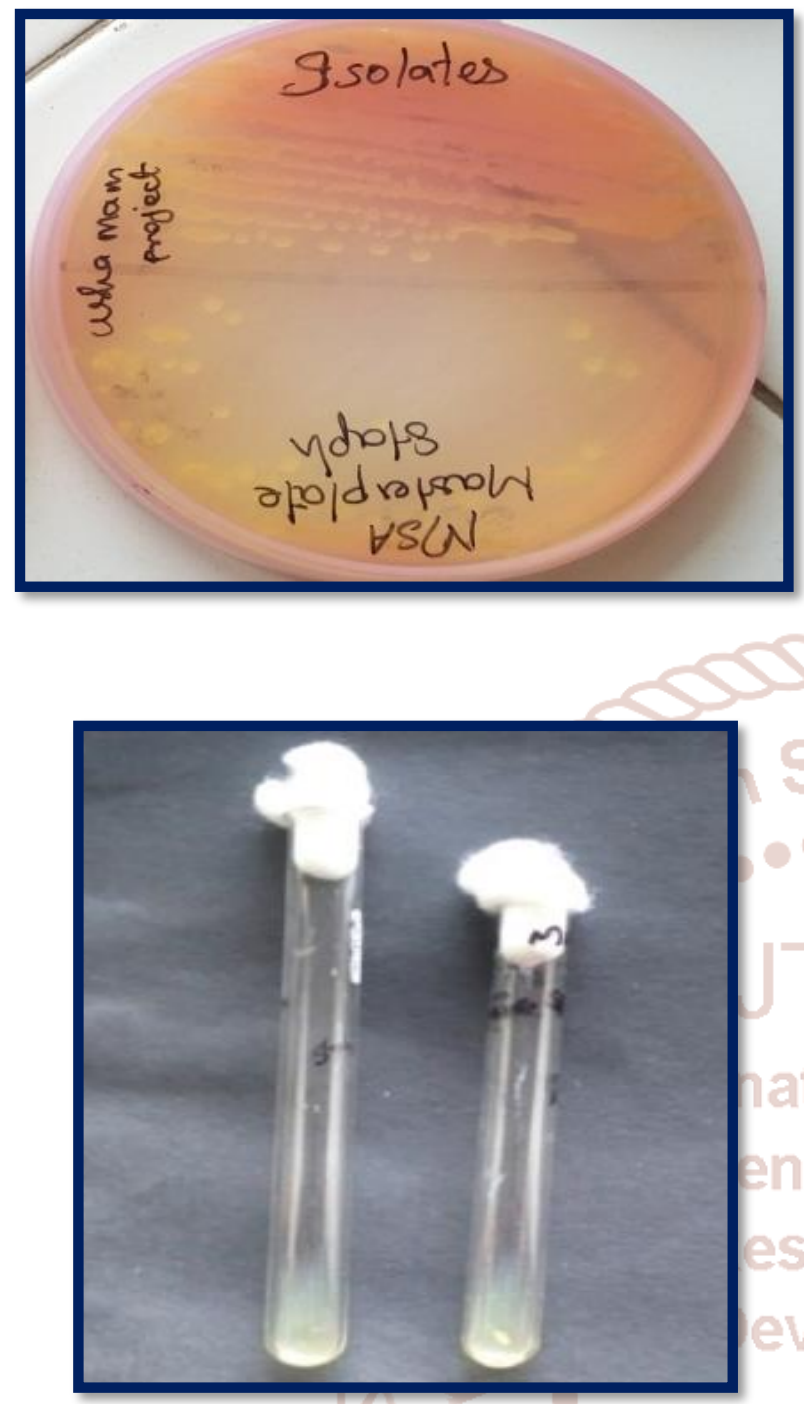

Coagula se test - Positive for isolate from coin

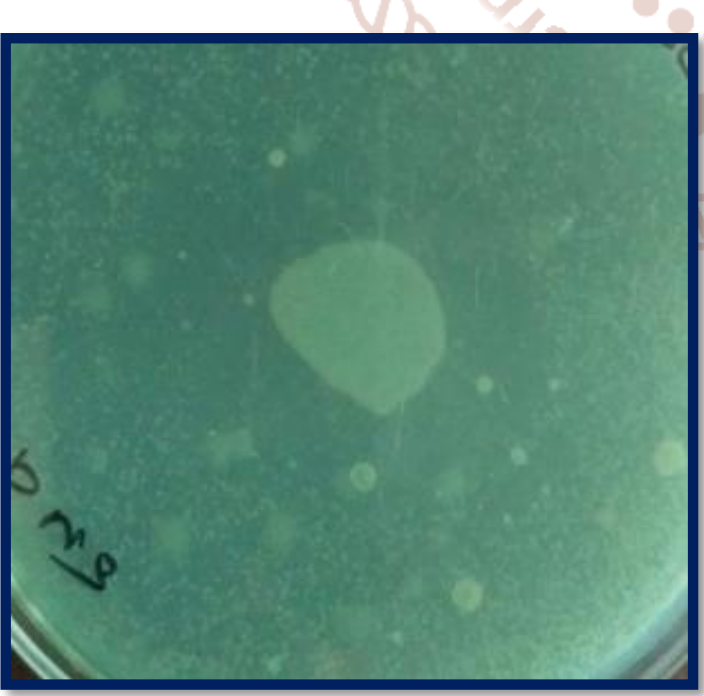

DNAse test - Positive for isolate Staphylococcus aureus from coin
Antibiotic sensitivity test for S.aureus isolate from coin

S. aureus was found highly sensitive to Amikiacin and resistant to the antibiotics such as Ceftriax one, Cefixime, Amorphicilin

\begin{tabular}{|c|c|c|}
\hline SI.No & Antibiotics & Zone Of Inhibition \\
\hline 1. & Vancomycin & $13 \mathrm{~mm}$ \\
\hline 2. & Erythromycin & $25 \mathrm{~mm}$ \\
\hline 3. & Clindamycin & $17 \mathrm{~mm}$ \\
\hline 4. & Penicillin & Resistant \\
\hline
\end{tabular}

\section{Antibacterial Activity of crude pigment extract}

The antibacterial activity of crude ethanol pigment of Staphylococcus aureus was determined by inoculating Staphylococcus aureus isolate in to Nutrient broth and incubated for $24 \mathrm{hrs}$ at $37^{\circ} \mathrm{C}$.The turbidity of broth was compared to $0.5 \mathrm{~N}$ McFarland solutions. The lawn was prepared using Staphylococcus aureus isolate on Muller Hinton agar. The wells were cut using sterile well puncher and one milli gram of pigment extract was suspended in $100 \mu \mathrm{l}$ of acetone and $900 \mu \mathrm{l}$ nutrient broth. Different concentrations of pigment extracts ranging from500, 250, 125, 62.5 $\mu 1$ were loaded in to wells using water as control. Muller Hinton agar plate was incubated at $37{ }^{\circ} \mathrm{c}$ for $24 \mathrm{hrs}$ and observed for Zone formation.

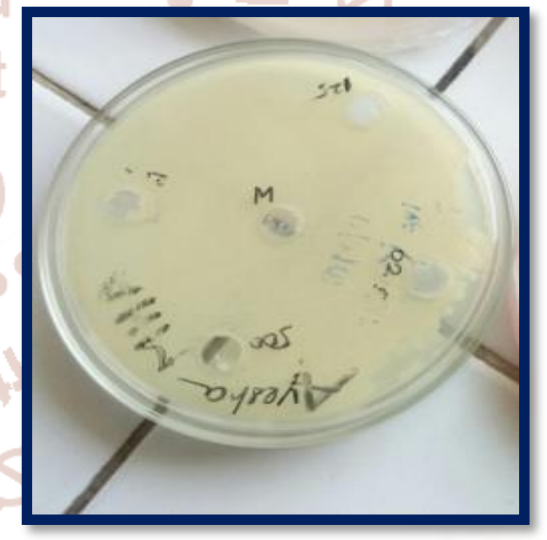

Well diffusion method for- staphylococcus species

\section{DISCUSSION}

The pathogen Staphylococcus aureus is Gram-positive cocci in clusters which forms golden colony on Nutrient agar. The most important characteristic feature of Staphylococcus aureus is its yellow to orange colour due to production of Staphyloxanthin. Staphyloxanthin is membrane bound carotenoid and plays an important role in antimicrobial activity the main aim of this study was to extract pigment and determine the antibacterial activity against Staphylococcus aureus isolated from coin exchanged among the crowded population. The UV Visible 
spectro photometric studies showed highest peak indicating estimation of pigment This study showed that crude acetone pigment extracts exhibited most potent antibacterial activity against Staphylococcus aureus isolate by performing well diffusion using different concentrations of crude pigment extract ranging from $500 \mu 1$ to $62.5 \mu \mathrm{l}$ exhibiting inhibitory values of $11 \mathrm{~mm}$ The isolate was found to be resistant to pigment extracts at concentration range of $250 \mu 1$ $125 \mu \mathrm{l}$ and $62.5 \mu \mathrm{l}$. Minimum bactericidal concentrations was performed and found to be turbid by showing cloudy appearance.

\section{Summary and Conclusion}

Staphyloxanthin is a secondary metabolite produced by Staphylococcus aureus during stationary phase which has a chemical formula of (C51H7808). Staphyloxanthin is a neutral molecule. The aim of the present study was to detect the role of Staphyloxanthin pigment production from $S$. aureus isolates against Staphylococcus aureus isolate from coin proving low antagonistic property. Staphylococcus aureus was sub cultured and inoculated in to Nutrient broth followed by incubation at $37^{\circ} \mathrm{c}$ for $48 \mathrm{hrs}$ in rotary shaker for production of pigment. The pigmented broth was centrifuged at $1500 \mathrm{rpm}$ for $30 \mathrm{mins}$. The supernatant was filtered using sterile what Mann filter paper. The filtrate was mixed with ethanol and kept in oven overnight to obtain crude extract. The crude extract was stored in sterile storage vials for antibacterial study. The coin was collected from public transport in crowded area and transferred to sterile Zip lock cover using sterile hand gloves. The coin was transferred to nutrient broth in flask and incubated at $37^{\circ} \mathrm{c}$. The turbidity was observed and microscopic examination was done by Gram staining technique and found to be Gram positive cocci in clusters. The broth culture was inoculated in to Nutrient agar and Mann itol salt agar and incubated for $24 \mathrm{hrs}$ at $37^{\circ} \mathrm{c}$. Coagula se and DNAse tests were performed to differentiate Staphylococcus spp. Antibiotic sensitivity tests was done to find out sensitivity of Staphylococcus .aureus isolate to antibiotics. The isolate was found to be highly resistant to Pencillin and sensitive to Erythromycin. The crude ethanol pigment was used against staphylococcus aureus in different concentrations ranging from $500 \mu 1$ to $62.5 \mu \mathrm{l}$ by well diffusion method. Maximum inhibition was found to be at different concentrations were found to be $11 \mathrm{~mm}$ at concentration range of 500. $\mu 1$. The current study reported that coin plays an important role $\mathrm{s}$ transmitting infections. It was concluded that coin acts as one of the factors for spread of infections. The Staphy lox an thin acts as an important antagonist and is a novel bio colour against Staphylococcus aureus is olate from coins. This study was done for the first time to the best of our Knowledge.

\section{Acknowledgements}

The Authors thank Ms Summera Rafiq, Associate Professor\& Head, P.G. Dept of Applied Microbiology for her valuable support and Ms Tharani. V of M. Sc II nd year, Microbiology for extended help in providing culture,

\section{REFERENCES}

1. Daum, R. S. 2008 Removing the golden coat of Staphylococcus aureus N. Engl. J. Med. 359, pp: 85-87

2. Marshall, J. H., and G. J. Wilmoth. 1981. Proposed pathway of triterpenoid carotenoid biosynthesis in Staphylococcus aureus: evidence from a study of mutants. J. Bacteriol. 147, pp: 914-919

3. Clauditz A. Resch A.; Wieland KP. Peschel A and Götz F 2006. Staphyloxanthin plays a role in the fitness of Staphylococcus aureus and its ability to cope with oxidative stress. Infect. Immun., 74(8), pp: 4950-4953

4. Pelz A, Wieland KP, Putzbach K, Hentschel P, Albert K, Götz F 2005. Structure and biosynthesis of staphyloxanthin from Staphylococcus aureus. J. Biol Chem. 280(37):32493-32498

5. Liu CI, Liu GY, Song Y, Yin F, Hensler ME, Jeng WY, Nizet V, Wang AH, Oldfield E 2008. "A cholesterol biosynthesis inhibitor blocks Staphylococcus aureus virulence". Science 319 (5868) pp: 391-94.

6. Rohmer, M., P. Bouvier, and G. Ourisson. 1979. Molecular evolution of membranes: structural equivalents and phylogenetic precursors of sterols. Proc. Natl. Acad. Sci. U. S. A. 76 pp: 847- 851

7. Pelz A, Wieland KP, Putzbach K, Hentschel P, Albert K, Götz F 2005. Structure and biosynthesis of staphyloxanthin from Staphylococcus aureus. J Biol Chem. 280(37) pp: 32493-32498 Al-Kazaz et. Al. Iraqi Journal of Science, 2014, Vol 55, No.4B, pp:1823-1832 1831

8. Hartmann, W., and H. J. Galla. 1978. Binding of polylysine to charged bilayer membranes: 
molecular organization of a lipid peptide complex. Biochim. Biophys. Acta 509, pp: 474-490.

9. Kim, J., M. Mosior, L. A. Chung, H. Wu, and S. McLaughlin. 1991. Binding of peptides with basic residues to membranes containing acidic phospholipids. Biophys. J. 60 pp:135-148.

10. Hammond, R. K. and White, D. C. 1970. Carotenoid Formation by Staphylococcus aureus. J. of Bacteriol. 103(1) pp: 191-198

11. Wlliam, B. W;Paul D.V.George ,M. G. Dorothy, J. Noel R. K. Wolfgang, L. Fred ,A. R. and Karl, S. 2009. Bergey's Manual of Systematic Bacteriology 2nd edition Com.pp: .392-433.

12. Grinsted, J., and Lacey R. C 1973. Ecological and genetic implications of pigmentation in Staphylococcus aureus. J. Gen. Microbiol. 75 pp: 259-267.
13. Marshall JH, Wilmoth GJ. 1981. Pigments of Staphylococcus aureus, a series of triterpenoid carotenoids. J Bacteriol; 147 pp: 900-913.

14. Wieland B, Feil C, Gloria-Maercker E, Thumm G, Lechner M, Bravo JM, Poralia K, Götz F 1994. Genetic and biochemical analyses of the biosynthesis of the yellow carotenoid 4,4'diaponeurosporene of Staphylococcus aureus. J. Bacteriol., 176(24) pp: 7719-7726.

15. Tao, N. Gao,Y. Liu,Y. and Ge, F. 2010. Carotenoids from the Peel of Shatian Pummelo (Citrus grandis Osbeck) and Antimicrobial Activity. American Eurasian J. Agric \& Environ. Sci., 7(1) pp: 110-115. 